\title{
Postgraduate and continuing medical education [EL(90)79]
}

From April 1991, the budget for postgraduate medical education will be held by the Regional Postgraduate Dean, who will use it to fund educational programmes for trainees. The key aim is to separate the costs of postgraduate training from the service costs which will meet from capitation funding. Budgets for continuing medical education -i.e. for consultants and other career grades - will be held at unit level and the costs will be recouped from income from service contracts.

Next year's budget will be based on estimates derived from direct costs currently identified. These budgets will be "protected" or ring-fenced.

To create these budgets, regions are at present attempting to obtain information on what is currently being spent at unit, district and regional levels.

It is imperative to ensure that all current costs are identified, for in the past they have been mixed with costs of service provision on a variety of budgets. Secretarial costs, study leave, photocopying, lecture fees, travelling expenses and so on have often been foregone or met from unit, university or medical stafiing budgets. It is essential to record all these costs if future allocations are to be adequate.

Since District Clinical Tutors will have responsibility for units' educational budgets, this may be the time to review the relationship between Psychiatric
Tutors, District Tutors and the Postgraduate Dean. Those responsible for rotational training schemes in psychiatry should ensure that the Psychiatric Tutor has a direct relationship with the Postgraduate Dean and holds the budget for postgraduate psychiatric training on behalf of the Postgraduate Dean. Otherwise these funds would be managed by the District Clinical Tutor or Clinical Tutor of a general unit.

The relationship between the Regional Postgraduate Dean and those responsible for psychiatric education in postgraduate medical schools, such as those in Exeter, Hull, Keele and Warwick and the London Postgraduate Medical Federation, requires classification.

Management of the budget for continuing medical education should be the responsibility of an appropriate consultant psychiatrist/Clinical Director/ Chairman of Division of Psychiatry.

As with all NHS managerial changes, the guidelines are lacking in detail and many local variations are possible. The first priority is to lay claim to the most advantageous budget and the second to determine the most effective administrative arrangements for its future management.

Dr Fiona Caldicott Dean

November 1990

\section{Guidelines for good medical practice in discharge and aftercare procedures for patients discharged from in-patient psychiatric treatment}

These Guidelines, prepared by a College Working Party, were circulated to the Membership in November 1989. The document was then discussed at a series of multidisciplinary meetings and amendments were made which were presented to Council at its recent meeting.

Council agreed that the present guidelines were unacceptable and should not be adopted. It was agreed that the College's original report should be redrafted in more general terms taking into account the views of the Royal College of General Practitioners when these were received. The new document will be presented to Council in due course and will be published in the Bulletin as soon as possible.

Dr ANN Gath

Registrar 